\title{
UPAYA MEMBANGUN PENDIDIKAN YANG BERKARAKTER DAN BEBRUDI PEKERTI
}

\section{Dorce Du'pa}

\author{
$\underline{\text { Institut Agama Kristen Toraja }}$
}

dorcedupa@gmail.com

\begin{abstract}
Abstrack:
Education is basically an effort to improve the ability of human resources so that they can become human beings who have character so that they can live independently. The school is one of the learning institutions instill values, form human beings with character and virtuousness through rooting. Character education programs will be successful in schools if all personnel in schools can work together with parents so that the educational goals expected by this nation can really be felt and can touch the positive values of the nation's children who are expected together.
\end{abstract}

Keywords: pendidikan yang berkarakter dan berbudi pekerti

\section{A. Pendahuluan}

Peruh di sadari bahwa globalisasi serta perkembangan ilmu pengetahuan dan teknologi yang luar biasa telah membuat dunia serba terbuka. Ketika terjadi peningkatan aktivitas lintas-batas dan komunikasi secara maya atau virtual keseluruh penjuru dunia dalam waktu singkat serta maju nya teknologi dan komunikasi maka hanya mereka yang siap yang bisa meraih kesempatan, globalisasi aka memicu perubahan mengalami metamorfosis menuju manusia terbuka. Pendidikan untuk membangun masyarakat yang lebih dewasa memecahkan konflik atau perbedaan pendapat dengancara damai, berhenti mencari kambing hitam, dan mau belajar mengatur diri sendiri karena pendidikan merupakan sarana untuk untuk membangun masyarakat dan bukan untuk saling menutup diri, saling mengasingkan diri, bukan untuk saling mencerca serta belajar untuk menemukan platform bersma di tengah-tengah perbedaan. Pendidikan merupakan sarana membangun semangat, pendidikan juga perluh di arahkan untuk meningkatkan kepercayaan diri bangsa dan bukan untuk menghancurkan harga diri dengan terus menerus mencerca diri sendiri.

Sistem pendidikan nasional di sebutkan bahwa pendidikan adalah usaha sadar dan terencana untuk mewujudkan suasana belajar dan proses pembelajaran agar peserta didik secara aktif menggebangkan potensi dirinya untuk memiliki kekuatan spiritual keagamaan, penggenalan diri, kepribadian,kecerdasan, akhlak mulia serta keterampilan yang di perluhkan dirinya, masyarkat, bangsa dan Negara. Dengan demikian dalam penyusunan standar Nasional pendidikan di sebutkan dalam salah satu fungsinya adalah bertujuan untuk menjamin mutu pendidikan nasional dalam rangka mencerdaskan 
kehidupan bangsa dan membentuk watak serta peradaban bangsa yang bermartabat oleh karena itu arah dari tujuan penyelenggaraan pendidikan sangat luhur dalam keinginannya mewujudkan manusia yang bermartabat yang memiliki karakter yang mulia.

\section{B. TUJUAN DAN MANFAAT}

Tujuan pembuatan makalah ini adalah untuk mengetahui :

1. Pentingnya pendidikan yang berkarakter

2. Peran pendidik dalam berbudi pekerti

Adapun manfaat pembuatan makalah ini adalag agar dapat memperluas wawasan dan pengetahuan pembaca tentang "Upaya membangun pendidikan yang Berkarakter dan Berbudi Pekerti”

\section{Pembahasan}

\section{Pentingnya pendidikan yang berkarakter}

Salah satu manfaat dari pendidikan yakitu menyelaraskan kehidupan, memberikan informasi dan pemahaman, menciptakan generasi penerus bangsa mencegah terbentuknya generasi yang " Bodoh ", mencegah terjadinya tindak kejahatan, mengajarkan fungsi sosial dalam masyarakat, menigkatkan produktivitas, membentuk karakter bangsa, memperbaiki cara berpikir indivdu dan meningkatkan tafar hidup manusia. Oleh karena itu sangat di perluhkan di era sekarang ini karena dengan pendidikan akan maju Negara ini, pendidikan karakter ini sangat erat hubungannya dengan pendidikan moral di mana tujuannya yakitu untuk membentuk dan melatih kemampuan individu secara terus menerus untuk penyempurnaan diri kearah hidup yang lebih baik. ${ }^{1}$ Guru adalah model atau teladan yang paling penting bahkan ampuh memengaruhi para murid, karakter dan kepribadian seorang guru lebih dominan berpengaruh pada kehidupan murid-muridnya di bandingkan materi ajarnya. Memang tidak ada ukuran yang rigid untuk mengukur besarnya pengaruh, namun satu hal yang kita ketahui berama adalah kehidupan exemplari dari seorang guru bisa berdampak kuat bagi pembentukan hidup murid-muridnya. Dengan Karakter dan kepribadian yang di bentuk melalui katalisasi minat dan antusiasme juga merupakan modal yang besar untuk mencapai tau memperoleh sesuatu.Kemudian pada akhirnya seorang murid dengan sadar akan berusaha menarik diri dari hal-hal yang dapat menganggu belajarnya kemudian membentuk dan mencari lingkungan yang memungkinkan ia makin mampu menuangkan kreatifitas dan sanggup menaikkan potensi dirinya. Jadi bagi diri minat akan berpengaruh baik terhadap berlangsungnya proses belajar peserta didik. $^{2}$ Melalui karakter standar-standar batin yang terimplementasi dalam berbagai

\footnotetext{
${ }^{1}$ https://Koran bogor.com/bogor-now/pentingnya-pendidikan-dalam-pendidikan-di-indonesi/

${ }^{2}$ Rannu Sandera. "'EXEMPLARY,Menemukan Kunci Pendidikan Iman Bagi Anak dan Keluarga Pembelajaran Agama di Sekolah" ." http;//osf.io/bmtrk/, n.d.
} 
bentuk kualitas diri yakitu karakter diri yang di landasi dengan nilai-nilai serta cara berpikir berdasarkan nilai -nilai tersebut dan terwujud di dalam perilkau. Sementara itu, Indonesia Heritage foundation yang di kutip Hasanah merumuskan beberapa bentuk karakter yang harus ada di dalam setiap individu bangsa Indonesia di antaranya yakitu cinta kepada Allah, dan alam semesta beserta isinya, tanggung jawab, disiplin mandir, jujur, hormat dan santun, kasih sayang, peduli dan kerja sama, percaya diri, kraetif, kerja keras dan pantang menyerah, keadilan dan kepemimpinan, baik dan rendah hati dan toleransi, cinta damai dan persatuan

\section{Peran pendidik dalam berbudi pekerti}

Pendidikan budi pekerti adalah untuk mengembangkan karakter di sekolah dimana proses pendidikan di mulai dengan cara mengintegrsikan nilai-nilai budi pekerti kedalam kandungan kurikulum, setipa karakter akan di kembangkan harus terwujud di dalam kandngan setiap mata pelajaran wujudnya dapat melalui tugas-tugas mata pekerjaan rumah bahan kajian, simulasi dan juga terwujud di dalam peraturan akademik yang lain di sekolah. Melalui cara ini peserta didik akan terlatih secara terpola yang menjadikan peserta didik terbiasa untuk berbuat kebaikan terhadap sesama dan sebagai bagian dari proses pembentukan karakter anak bangsa, pendidikan budi pekerti juga di harapkan mampu menjadi pondasi utama dalam rangka mencerdaskan kehidupan bagsa. Jadi pendidikan Budi pekerti di katakana sebagai pendidikan internalisasi nilai dan sekaligus memperaktekannya dalam kehodipan sehari-hari msks kegiatan ekstra kurikuler merupakan wahana yang cukup terbukauntuk menambah pendidikan budi pekerti. ${ }^{3}$

Pendidikan yang berpola asketisme dapat menjadikan manusia untuk memiliki akal selanjutnya dan memapukan ia berpikir lebih panjang dalam membuat perencanaan hidupnya, dan juga pengendalian diri dalam menunda atau menolak sesuatu yang kurang bermanfaat untuk sesuatu yang lebih berguna dan membahagiakan memerluhkan proses latihan melalui pendidikan disiplin kendali diri. ${ }^{4}$ Oleh karena itu peserta didik perluh memiliki motivasi terutama motivasi intrinsic dimana motivasi intrinsic ini sangat di butuhkan sebab ifatnya murni dan berdaya bertana lama, motivasi dapat menciptakan peserts didik yang berkualitas. Idealnya motivasi intrinsik akan semakin berpengaruh jika di topang dengan adanya motivasi dari luar misalnya sikap orang, pemilihan lingkungan dukungan guru dab perggrup, nasihat pemimpin rohani dapat men-empower motivasi intrinsik untuk lebih kuat.

\section{KESIMPULAN DAN SARAN}

1. Kesimpulan

\footnotetext{
${ }^{3}$ http://journal.iain-manado.ac.id/index.php/PP/article/view.740

${ }^{4}$ Rannu Sanderan, Disiplin Asketisme dan Harmoni Kotribusi Disiplin Diri bagi Pengembangan Pendidikan Kristen, http://osf,io/frsnz/,
} 
Pendidikan karakter adalah proses pendidikan secara holistic yang menghubungkan dimensi moral dengan ranah sosial dalam kehicupan peserta didik sebagai pondasi bagi terbentuknya generasi yang berkualitas yang mampu hidup mandiri dan mampu memiliki prinsip suatu kebenaran yang dapat di pertanggungjawabkan. Pendidikan yang mengembangkan karakter adalah bentuk pendidikan yang bisa membantu mengembangkan sikap etika, moral dan tanggungjawab, memberikan kasih sayang kepada Anak didik dengan menunjukan dan mengajarkan karakter yang bagus. Masyarakat di luar lembaga pendidikan, seperti Keluarga, masyarakat umum dan Negara juga memiliki tanggung jawab moral untuk mengintegrasikan pembentukan karakter dalam konteks kehidupan mereka

2. Saran

Sekolah adalah sebagai tempat kedua dari lingkungan kelurga perluh untuk memciptakan kondisi yang lebih baik dalam memberikan pembentukan karakter peserta didik. Oleh karena itu sekolah perluh menciptakan hubungan dengan peserta didik dengan memperlakukan dengan lemah lembut, tetapi tetap dalam kondisi disiplin kepada peserta didik. Sekolah juga memberikan dorongan anak untuk tetap berkreasi tanpa ada tekanan dan memberikan penghargaan bagi peserta didik yang berprestasi. Selanjutanya perluh adanya peran dari masyarakat lingkungan, media,masa dalam membentuk karakter anak hinggah semua komponen bangsa ikut bertanggungjawab dalam membentuk karakter anak untuk bisa mandiri menjadi manusia yang bermanfaat bagi dirinya keluarga dan bangsa 


\section{DAFTAR PUSTAKA}

Sanderan, Rannu. EXEMPLARY,Menemukan Kunci Pendidikan Iman bagi Anak dan Keluarga Pembelajaran Agama di Sekolah, http;//osf.io/bmtrk/,n.d.

Sanderan Rannu, Disiplin Asketisme dan Harmoni Kontribusi Disiplin Bagi Penggembangan Pendidikan Kristen, http://osf,io/frsnz/,

https://Koranbogor.com/bogor-now/pentingnya-pendidikan-dalam-pendidikan-di-indonesia

http://Journal.iain-manado.ac.id/index.php/PP/aericle/view.740 